\section{Assessment of the patient safety culture in primary health care}

Avaliação da cultura de segurança do paciente na atenção primária à saúde Evaluación de la cultura de seguridad del paciente en la atención primaria a la salud

Nathalia Malaman Galhardi'

Camila Eugenia Roseira ${ }^{1}$

Fabiana de Souza Orlandi ${ }^{1}$

Rosely Moralez de Figueiredo ${ }^{1}$

Keywords

Patient safety; Organizational culture; Quality of health care; Primary health care

Descritores

Segurança do paciente; Cultura organizacional; Qualidade da assistência à saúde; Atenção primária à saúde

Descriptores Seguridad del paciente; Cultura organizacional; Calidad de la atención de salud; Atención primaria de salud; Enfermería

Submitted

April 28, 2018

Accepted July 30, 2018

\section{Abstract}

Objective: Assess the professionals' perception on the patient safety culture in primary health care.

Methods: quantitative, cross-sectional, descriptive survey, using the questionnaire "Pesquisa sobre Cultura de Segurança do Paciente para Atenção Primária", which assesses 12 dimensions of the patient safety culture. Dimensions scoring $75 \%$ or higher were considered positive. Results: The dimensions "information exchange with other institutions" (79\%), "teamwork" (79\%), "patient care tracking/follow-up" (80\%), "patient safety and quality problems" (83\%), while "leadership support for patient safety" (47\%) showed to be a weak area. A significant difference was found when comparing the variables length of experience and professional category with the average percentages of positive answers. Conclusion: The results showed that the Primary Health Care professional perceived the dimensions of the patient safety culture positively, and only "leadership support for patient safety" was considered as a weak area.

\section{Resumo}

Objetivo: Avaliar a percepcão dos profissionais acerca da cultura de segurança do paciente na atenção primária à saúde.

Métodos: pesquisa quantitativa transversal, descritiva do tipo survey, utilizando o questionário "Pesquisa sobre Cultura de Segurança do Paciente para Atenção Primária", que avalia 12 dimensões da cultura de segurança do paciente. Foram consideradas positivas as com escores maior ou igual a $75 \%$.

Resultados: As dimensões "troca de informações com outras instituições" (79\%), "trabalho em equipe" (79\%), "acompanhamento do cuidado do paciente" (80\%), "seguranca do paciente e problemas de qualidade" (83\%) foram consideradas positivas para a cultura de seguranca do paciente, enquanto "suporte da liderança" (47\%) demonstrou-se como área fraca. Houve diferença significativa na comparação das variáveis tempo de serviço e categoria profissional com a média das porcentagens de respostas positivas.

Conclusão: Os resultados mostraram que os profissionais da Atenção Primária à Saúde tiveram percepções positivas quanto às dimensões da cultura de segurança do paciente, e apenas "suporte da liderança" foi considerada como área de fragilidade.

\section{Resumen}

Objetivo: Evaluar la percepción de los profesionales sobre la cultura de seguridad del paciente en la atención primaria a la salud.

Métodos: Investigación Cuantitativa, transversal, descriptiva del tipo survey, utilizando el cuestionario "Encuesta sobre Cultura de Seguridad del Paciente de Atención Primaria", el cual evalúa 12 dimensiones de la cultura de seguridad del paciente. Se consideraron positivas las puntuaciones superiores o igual al $75 \%$

Resultados: Las dimensiones de "intercambio de información con otras instituciones" (79\%), "trabajo en equipo" (79\%), "monitoreo de la atención al paciente" (80\%), " seguridad del paciente y problemas de calidad" (83 (\%) fueron consideradas positivas para la cultura de seguridad de paciente, mientras que el "soporte del liderazgo" (47\%) se demostró como área débil. Hubo una diferencia significativa en la comparación de las variables tiempo de servicio y categoría profesional con el promedio de los porcentajes de respuestas positivas.

Conclusión: Los resultados mostraron que los profesionales de Atención Primaria a la Salud tuvieron una percepción positiva sobre las dimensiones de la cultura de seguridad del paciente, y solo el " apoyo del liderazgo" se consideró como zona frágil.

\section{Corresponding author}

Nathalia Malaman Galhardi

http://orcid.org/0000-0002-2064-4036

E-mail: nathymalaman@hotmail.com

\section{DOI}

http://dx.doi.org/10.1590/1982-

0194201800057

\section{How to cite:}

Galhardi NM, Roseira CE, Orlandi FS, Figueiredo RM. Assessment of the patient safety culture in primary health care. Acta Paul Enferm. 2018;31(4):409-16. 


\section{Introduction}

Patient safety, defined as the reduction of unnecessary damage to an acceptable minimum in health care, is acknowledged as a fundamental dimension of quality in health. ${ }^{(1)}$

Primary Health Care (PHC) is considered a key component of the Health Care Network, which proposes actions and health services of different technological densities in order to guarantee the integrality of care, through technical, logistic and management support systems. ${ }^{(2)}$

As it is not directly linked to high-tech procedures, PHC may be thought of as a safe and secure environment. It is known that Adverse Events (AEs), defined as incidents that result in some harm to the patient, occur in this health setting though. There are still many knowledge gaps regarding this issue and difficulty to measure the types of incidents that occurred. The studies are still incipient in this field, despite the greater visibility of the subject in Brazil, after the initiative to create the National Patient Safety Program (PNSP). ${ }^{(3,4)}$

We emphasize this scenario, based on a study carried out in Brazil, at a Family Health Strategy service (ESF), which evaluated the occurrence of incidents in the patient in relation to the severity, type and the factors contributing to this occurrence. It was concluded that, although PHC attends to patients with less technical complexity, $82 \%$ of the incidents caused damage to the patient, many of them with very high severity - permanent damage (25\%) or death $(7 \%) .{ }^{(3)}$

It is understood that it is necessary to invest in the recognition of the patient safety culture, so that it is possible to examine to what extent the perceptions, behaviors and competences of individuals and groups influence the patient safety outcomes and the quality of care. ${ }^{(5)}$

Therefore, evaluating the patient safety culture in PHC is an important step towards improving the quality and safety of care, considering the scope of this scenario in the health care network. The objective of this study, therefore, is to evaluate the professionals' perception about the patient safety culture in the PHC environment, considering that this eval- uation may point out new guidelines for strengthening patient safety in this health care setting.

\section{Methods}

This is a quantitative, cross-sectional, descriptive survey carried out in PHC, in a city with an estimated population of 298,701 inhabitants, in the interior of the State of São Paulo.

The PHC network of the city consists of 32 Family Health Centers (CSF), of which 17 are mixed services, i.e. they serve as Basic Health Services (UBS) and Family Health Strategy (ESF).

Of the 564 professionals performing care functions in these CSFs, 106 were excluded because they were on vacation and/or leave for health treatment or maternity during the data collection period (from December 2016 to March 2017). In total, 458 professionals were invited, and 240 accepted to participate in the process. Approval for the study was obtained from the Research Ethics Committee of the Federal University of São Carlos (Opinion No. 1.818.070), and resolution 466/12 was fully complied with.

To do this, the questionnaire "Pesquisa sobre Cultura de Segurança do Paciente para Atenção Primária" was applied, ${ }^{(6)}$ Brazilian version of the Medical Office Survey on Patient Safety Culture, created by the Agency for Healthcare Research and Quality. The authors authorized the use of the instrument adapted and validated for Brazil. ${ }^{(6)}$

The professionals were mostly approached in group, except those who were attending at that moment, later invited individually. This permitted inviting the largest number of people with minimal interference in the service routine. The delivery of the questionnaire and the Free and Informed Consent Term occurred on a date agreed with the team.

The instrument is composed of 52 items, with alternative answers on a Likert scale that permits evaluating twelve dimensions of the patient safety culture: open communication, communication about the error, information exchange with other institutions, office process and standardization, or- 
ganizational learning, overall perception of patient safety and quality, leadership support for patient safety, patient care tracking/ follow-up, patient safety and quality problems, staff training, teamwork and work pressure and pace. ${ }^{(6)}$

Data was organized and stored in Microsoft Excel $^{\oplus}$ spreadsheets. For treatment and analysis, the Statistical Package for the Social Sciences (SPSS) version 22.0 was used.

For the descriptive analysis of the data, the response frequency of each item and the average for each dimension were calculated. Following the recommendation of the original instrument, ${ }^{(7)}$ these dimensions were rated as strong, when $75 \%$ or more of participants answered I totally agree/I agree or frequently/always to positive questions; and I totally disagree/I disagree or never/rarely for negative questions. Dimensions were classified as weak when $50 \%$ or more of the participants answered negatively, choosing I totally disagree/I disagree or never/ rarely for positive questions, or I totally agree/I agree, always/frequently for negatively questions. ${ }^{(7)}$

To test the reliability of the answers, Cronbach's alpha was calculated for each dimension and for the survey as a whole. Results equal or superior to 0.7 were considered satisfactory. ${ }^{(8)}$

The Kolmogorov-Smirnov test was executed, which indicated absence of normality of the data. Therefore, the Kruskal-Wallis Test was applied to assess the comparison of means of the positive answer percentages related to the variables "professional category" and "length of experience". For the statistical test, significance was set at 5\% ( $\leq \leq 0.05)$.

\section{Results}

Fifty-two percent (240) of the professionals participated, including: physician (18), nurse (14), dentist (6), social worker (2), psychologist (2), pharmacist (4), physiotherapist (1), manager (15), administrative staff (20), Community Health Agent (83), nursing auxiliary (9), pharmacy aide (6) and oral health aide (1).

As for the length of experience at the service, the results varied, with 87 professionals working from two months to less than three years; 80 from three to less than 11 years and 41, for 11 years or more; only three had been working less than two months and 21 did not respond. Of these, 158 (76\%) have a workload of 33 to 40 hours a week.

Regarding the reliability of the answers, the general Cronbach's Alpha coefficient obtained was 0.93. Thus, the following dimensions were excluded: "open communication" ( $\alpha=-0.17)$, "communication about the error" ( $\alpha=0.48)$, "process standardization" (0.55), "team training" $(\alpha=0.56)$ and "work pressure and rhythm" $(\alpha=0.59)$.

The analyzed dimensions are represented in table 1 , which indicates the dimensions that obtained a satisfactory Cronbach's alpha coefficient by positive perception percentage.

Table 1. Positive perception associated with the items of the patient safety culture dimensions

\begin{tabular}{|c|c|}
\hline Items per patient safety culture dimension & $\begin{array}{c}\text { Positive } \\
\text { perception } \\
n(\%)\end{array}$ \\
\hline \multicolumn{2}{|l|}{ 1. Teamwork $(\alpha=0.670)$} \\
\hline C1: When someone gets really busy, others help out & $191(80)$ \\
\hline $\mathrm{C} 2$ : There is a good relationship between the physicians and other professionals & 205(86) \\
\hline C5: We treat each other with respect & 188(79) \\
\hline C13: We value teamwork in patient care & $161(71)$ \\
\hline \multicolumn{2}{|l|}{ 2. Patient care tracking/follow-up ( $\alpha=0.754$ ) } \\
\hline D3: The patients are reminded when they need to schedule a routine appointment & 208(90) \\
\hline D5: We document how the chronic patients follow the treatment & $160(76)$ \\
\hline D6: The service follows up when it does not receive a report from another service & $123(65)$ \\
\hline D9: We follow up with patients who need monitoring & 200(89) \\
\hline \multicolumn{2}{|l|}{ 3. Leadership support for patient safety ( $\alpha=0.712)$} \\
\hline E1R: They are not investing enough resources to improve the quality & $52(26)$ \\
\hline E2R: They overlook patient care mistakes that happen over and over & $113(58)$ \\
\hline E3: They place priority on improving patient care processes & $119(59)$ \\
\hline E4R: Decisions are made based on what is best for the service rather than for the patient & $89(46)$ \\
\hline \multicolumn{2}{|l|}{ 4. Organizational learning ( $\alpha=0.702)$} \\
\hline $\mathrm{F} 1$ : When there is a problem, we see if we need to make any change & 179(86) \\
\hline F5: The service is efficient at changing processes and preventing the same problems. & 130(63) \\
\hline F7: After making changes, we check to see if they work & $145(72)$ \\
\hline \multicolumn{2}{|l|}{ 5. Overall perception of patient safety and quality ( $\alpha=0.724)$} \\
\hline F2: Our work processes are good at preventing mistakes & $146(70)$ \\
\hline F3R: Mistakes happen more than they should & 137(68) \\
\hline F4R: It is just by chance that we don't make more mistakes & $148(74)$ \\
\hline F6R: Getting more activities done is more important than the quality of care & $131(67)$ \\
\hline \multicolumn{2}{|l|}{ 6. Patient safety and quality problems ( $\alpha=0.842)$} \\
\hline A1: A patient was unable to get an appointment within 48 hours for a serious problem & 148(77) \\
\hline A2: Another patient's chart was used when attending to a patient & 173(89) \\
\hline A3: A patient's chart was not available when needed & $167(82)$ \\
\hline A4: A patient's information was filed into the wrong patient's chart & 167(90) \\
\hline A5: Medical equipment was not working properly & 152(82) \\
\hline A6: The patient returned to the service to clarify/correct the prescription & 154(72) \\
\hline A7: A patient's medication was not reviewed during the appointment & 123(90) \\
\hline A8: The laboratory/imaging tests were not done when necessary & $131(82)$ \\
\hline A9: The laboratory test results were not available & 147(78) \\
\hline A10: An abnormal result from a test was not assessed in due time & 132(90) \\
\hline \multicolumn{2}{|l|}{ 7. Information exchange with other institutions ( $\alpha=0.901)$} \\
\hline B1: Problem with imaging/laboratory centers in the network & $165(78)$ \\
\hline B2: Problems with other health services in the care network & $169(76)$ \\
\hline B3: Problems with pharmacies & 170(79) \\
\hline B4: Problems with hospitals & 134(82) \\
\hline
\end{tabular}


The general average percentages of positive answers in the dimensions that obtained a satisfactory Cronbach's alpha coefficient are displayed in table 2 .

Table 2. Dimension of patient safety culture associated with general average percentage of positive answers

\begin{tabular}{lc}
\hline Dimensions & $\begin{array}{c}\text { General average positive answers } \\
(\%)\end{array}$ \\
\hline Patient safety and quality problems & $83^{\star}$ \\
Patient care tracking/follow-up & $80^{\star}$ \\
Teamwork & $79^{\star}$ \\
Information exchange with other institutions & $79^{\star}$ \\
Organizational learning & 74 \\
Overall perception of patient safety and quality & 70 \\
Leadership support for patient safety & $47^{\dagger}$ \\
\hline
\end{tabular}

*Strong dimensions for patient safety culture; 'Weak dimension

For the variable "length of experience", "organizational learning" and "leadership support" presented a significant difference. The shorter the length of experience, the higher the positive perception (Table 3). What the professional category is concerned, physicians scored the highest for positive perception in the "patient safety and quality problems" and "teamwork" dimensions (Table 3).

Table 3. Positive answers in each dimension of the patient safety culture

\begin{tabular}{lcccc}
\hline Variables & $\begin{array}{c}\text { Organizational } \\
\text { learning } \\
\mathbf{n}(\%)\end{array}$ & $\begin{array}{c}\text { Leadership } \\
\text { support } \\
\mathbf{n}(\%)\end{array}$ & $\begin{array}{c}\text { Patient } \\
\text { safety } \\
\mathbf{n}(\%)\end{array}$ & $\begin{array}{c}\text { Teamwork } \\
\mathbf{n}(\%)\end{array}$ \\
\hline 1. Length of experience & & & & \\
Less than 2 months & $2(100)$ & $2(87)$ & $120(50)$ & $221(92)$ \\
2 months to 3 years & $87(84)$ & $87(59)$ & $163(68)$ & $194(81)$ \\
3 to 11 years & $166(69)$ & $144(60)$ & $151(63)$ & $187(78)$ \\
11 years or more & $199(83)$ & $108(45)$ & $168(70)$ & $202(84)$ \\
p-value* & 0.031 & 0.033 & 0.535 & 0.643 \\
2. Professional category & & & & \\
Physician & $18(85)$ & $18(61)$ & $17(80)$ & $18(100)$ \\
Nursing team & $38(78)$ & $37(47)$ & $49(72)$ & $49(81)$ \\
Manager & $15(80)$ & $1(75)$ & $14(74)$ & $15(72)$ \\
Administrative team & $14(78)$ & $11(66)$ & $16(56)$ & $18(71)$ \\
CHA & $64(80)$ & $65(60)$ & $79(68)$ & $81(77)$ \\
Others & $15(76)$ & $11(59)$ & $22(48)$ & $23(84)$ \\
p-value* & 0.831 & 0.169 & 0.008 & 0.001 \\
\hline
\end{tabular}

${ }^{*}$ Kruskal-Wallis test; ${ }^{\mathrm{C}} \mathrm{CHA}$ - Community Health Agent; Others - dentist, social worker, psychologist, pharmacist, physiotherapist, speech therapist, nursing auxiliary, pharmacy aide, oral health aide

\section{Discussion}

Creating a positive culture that promotes patient safety is one of the main challenges health organizations face. ${ }^{(5)}$ To this end, it is important to emphasize the participation of all health staff in promoting a positive safety culture.
Considering the lack of tradition in Brazil in evaluating the safety culture, particularly in PHC, the $52 \%$ response rate obtained can be considered satisfactory. Another favorable point was the participation of 15 different professional categories, ensuring a broad evaluation of the safety culture. In this sense, the importance of the engagement of all is affirmed, because the organizational culture influences the management style adopted and, consequently, it determines organizational changes. ${ }^{(9)}$

Due to the scarcity of publications related to the subject in Brazil, the comparisons of this research were based on international publications. Although the format of PHC is very diverse around the world, a standardized tool was used, permitting comparisons of similar aspects, reinforcing the importance of using tools validated for the Brazilian reality.

Like this research, a study carried out in Turkey compared the variable "professional category" and the positive responses, showing that the medical professional perceives the dimensions "open communication" ( $p<0.01)$ and "communication about the error" ( $p<0.01)$ more positively. ${ }^{(10)}$ In parallel, an Iranian research showed that the manager presented the highest scores for all dimensions $(p<0.001) .^{(11)}$

On the other hand, a Brazilian study found no difference among the categories: nursing technicians, nurses and community health agents regarding safety attitudes. ${ }^{(12)}$

As for the comparison of the dimensions related to length of experience, unlike our study, an Iranian study found no relation between them. ${ }^{(11)}$

On the other hand, a Spanish study that evaluated residents in family and community medicine found that first-year residents had the highest positive scores for "information exchange with other institutions" ( $p=0.007)$, "open communication" ( $p=$ $0.01)$, "staff training" ( $p=0.009)$ and "overall perception of patient safety and quality" $(p=0.02) .^{(13)}$

On the low reliability of the responses for the dimensions "open communication", "communication about the error", "office process and standardization", "staff training" and "work pressure and pace", it is worth noting that all these dimensions are interrelated and linked to aspects of communication, education and the work process, 
suggesting possible weaknesses in these aspects of the work environment.

Of the other dimensions evaluated, teamwork is the collective work modality that opposes the independent and isolated way in which health professionals usually carry out their work. ${ }^{(14)}$ It is considered essential for the proper functioning of the work process in PHC, in which the dialogue should favor the approximation among the different actors, clearly realizing that all partial knowledge only gains meaning when shared in the group. ${ }^{(15)}$

In this study, the "teamwork" dimension was evaluated as strong for the patient safety culture, reaching an average $79 \%$ of positive responses. Other investigations, which evaluated teamwork within and among services, also obtained high positive scores. ${ }^{(10,13,16)}$ A Brazilian study on safety attitudes also identified teamwork as a strong element for the patient safety culture. ${ }^{(12)}$

These studies suggest that teamwork is recognized as a strong element in the safety culture, in pursuit of changes and improvements in the quality of patient safety.

According to the literature, ${ }^{(17)}$ there are four modes of learning within organizations: learning from others, from the mistakes, from the data obtained and through unexpected responses.

Learning from others occurs through experiences revealed in conversations or in publications. In turn, learning from mistakes happens in the identification and analysis of one's own mistakes. Learning from the use of the data obtained, then, means using the results to provide feedback and to drive the organizational performance. Finally, learning from unexpected responses happens when there is constant vigilance and prevention of events. Thus, by looking at the less developed modes of organizational learning, faster progress in patient safety can be promoted. ${ }^{(17)}$

Despite the positive perception of the "organizational learning" dimension, when the theme is not guilt for the error, studies show low positive scores for non-punitive response to error, showing weakness in this aspect. ${ }^{(10,13,16)}$

Although the dimension "communication about the error" did not reach satisfactory reliability in this study, the item "the team at this service believes that errors can be used against them" stands out, as $49 \%$ of the participants agreed with the statement, revealing that the culture of fear is present. A similar situation was found in a study on safety attitudes, in which the "error" variable was the least relevant for the professionals, demonstrating the weakness of this aspect. ${ }^{(12)}$

Thus, it can be identified that the learning mode from errors needs improvements. The professionals need to be aware that the occurrence of error and guilt can be alternatives to transform it into a new chance to discuss, improve care and prevent new events related to the same cause from happening. ${ }^{(12)}$

The "patient care tracking/follow-up" dimension should be understood as a prominent area for PHC. In a longitudinal conceptual review, the authors affirm that patient monitoring over time by PHC professionals is a central feature of this care level. ${ }^{(18)}$

In this research, this dimension obtained a score of $80 \%$ of positive responses, being classified as a strong area for the safety culture. The results were similar to those of the Spanish study, in which the rate of positive responses was $71 \%{ }^{(13)}$ Only a different result was found in the city of Al-Mukala, Yemen, which identified fragility in this dimension and concluded that patients were not followed up/ monitored when necessary. ${ }^{(19)}$

Fragilities in patient follow-up/monitoring may lead to visits to other health facilities for routine care and problems in the quality of documents that make it difficult to service the longitudinal bond. ${ }^{(18)}$

Another important feature to ensure the proper functioning of care in PHC is the exchange of information among institutions in a complete, precise and timely manner. This was considered a strong area in this study but, in two other studies ${ }^{(13,16)}$, they were classified as fragilities, reaching only $47 \%$ of positive responses.

Regarding the situations that affect patient safety, $83 \%$ of the professionals had a positive perception and believe that there are few problems related to access, patient identification, medical records, charts, equipment, medication and diagnoses. 
Contrary to the professionals' perception in this research, however, a Brazilian study identified that the most common types of PHC incidents were associated with medication and diagnostic errors. ${ }^{(20)}$

Regarding access, in a study carried out in a large city in the State of São Paulo, users describe it as something bureaucratic and time-consuming, both for scheduling and for care in the service, relating it to the lack of medical professionals and their high turnover in the UBS. ${ }^{(21)}$

Another study about the perception of the ESF professionals in relation to the quality of the services provided, in a city in the state of Espírito Santo - Brazil, showed that these professionals perceive that the care is offered positively, contributing to the strengthening and humanization of PHC. ${ }^{(22)}$

In this respect, although the compared studies were conducted in different ways, reflections emerge on the extent to which the user's perception may differ from the health professional's perception, in relation to the quality of the service provided, and how much this can influence the quality of patient safety.

Therefore, it is considered that the positive results obtained in this study may be related to the low rates of event reporting. Studies that asked about the frequency of event reporting identified that only $12 \%$ to $32 \%$ of the professionals mentioned that the errors were reported. ${ }^{(10,11,16)}$

As strategies to address the knowledge gap, in view of the fear of punishment and informal communication that leads to underreporting of AEs, there is communication and educational practice, which improves the interaction between leaders and professionals, ${ }^{(23)}$ corroborating the present findings, in which the dimension "leadership support" for the patient safety culture was considered critical. Improvements are urgently needed, as only $47 \%$ of the participants perceived the subject positively.

Leadership in PHC is seen as a key competency for the development of change, given its potential to drive the teamwork process. In addition, it was observed that, in the current reality, nurses are mainly acting as supervisors, assuming this position. ${ }^{(24)}$ This fact is similar to the city studied, where most of the service coordinators were nurses.
When relating organizational culture, leadership behavior and job satisfaction, there is a significant positive correlation among these elements, suggesting that good interaction between leaders and professionals contributes to the stimulus towards the achievement of the objectives the institution defined. ${ }^{(25)}$

Thus, the result found in this study reveals the weakness of leadership support for the patient's safety culture, which may arouse the reflection that this may influence attitudes and behaviors related to the subject, demonstrating the importance of leaders in identifying the aspects pointed out and implementing actions for the purpose of patient safety.

In view of the above, it is worth highlighting the importance of involving all professionals in the process of improving patient safety. Effective, attitude-based actions need to be developed, where the attitude and culture of front-line health professionals should induce desirable behavioral changes to improve patient safety. ${ }^{(26)}$

Regarding the limitations of the study, only the perception of the professionals involved was used, without incorporating other aspects such as document analysis, observations of professional practice, users' perception, among others. Also due to the sharing of physical space between UBS and USF, comparing the data between these services was not possible. In addition, due to the incipient nature of this kind of research in PHC, the answers may have been provided with little reflection on the subject.

\section{Conclusion}

The results showed that PHC professionals had positive perceptions on the dimensions of the patient safety culture and the quality of the service. It was revealed, however, that the "leadership support" dimension needs improvement, so that aspects pertaining to the patient safety culture occur effectively, based on educational and non-punitive practices. In order to identify the professionals' perceptions about the patient's culture, it is important to point out that, when the different categories present in these health services were observed, the medical 
staff showed a more positive perception in the dimensions "overall perception of patient safety and quality" and "teamwork" and that, the shorter the length of experience, the more positive the perception for "organizational learning" and "leadership support for patient safety". Therefore, it should be noted that, although incipient, assessing the professionals' perception about the patient safety culture in PHC is necessary to allow services to identify domains and variables that need attention, through an individual situational diagnosis, so that strategies can be outlined to put these components in practice in this care network.

\section{Acknowledgements}

To the Health Department and Basic Care Coordination of the city of Limeira, São Paulo for granting permission to use the place of study. To the Coordination for the Improvement of Higher Education Personnel (CAPES) for funding one year of the research.

\section{Collaborations}

Figueiredo RM contributed to the project design, data analysis and interpretation, writing of the article, critical review of the intellectual content and final approval of the version for publication. Roseira $\mathrm{CE}$, Orlandi FS contributed to the interpretation of the data, relevant critical review of the intellectual content and final approval of the version for publication.

\section{References}

1. Runciman W, Hibbert P, Thomson R, Van Der Schaaf T, Sherman H, Lewalle P. Towards an International Classification for Patient Safety: key concepts and terms. Int J Qual Health Care. 2009;21(1):18-26.

2. Arruda C, Lopes SG, Koerich MH, Winck DR, Meirelles BH, de Mello AL. Health care networks under the light of the complexity theory. Esc Anna Nery. 2015;19(1):169-73.

3. Marchon SG, Mendes Junior WV, Pavão AL. Characteristics of adverse events in primary health care in Brazil. Cad Saúde Pública. 2015;31(11):2313-30.
4. Mesquita KO, Silva LC, Lira RC, Freitas CS, Lira GV. Patient safety in primary health care: An integrative review. Cogitare Enferm. 2016;21(2):1-8.

5. Al Doweri HF, Al Raoush AT, Alkhatib AJ, Batiha MA. Patient's Safety Culture: Principles and Applications: Review Article. Eur Sci J. 2015;11(15):83-94.

6. Timm M, Rodrigues MC. Cross-cultural adaptation of safety culture tool for Primary Health Care. Acta Paul Enferm. 2016;29(1):26-37.

7. Sorra J, Gray L, Famolaro T, Yount N, Behm J. AHRQ Medical Office Survey on Patient Safety Culture: User's Guide [Internet]. Rockville, MD: Agency for Healthcare Research and Quality; June 2016. (AHRQ Publication No. 15(16)0051-EF (Replaces 08(09)-0059). [cited 2018 Jul 29]. Available from: https:// www.ahrq.gov/sites/default/files/wysiwyg/professionals/quality-patientsafety/patientsafetyculture/medical-office/userguide/mosurveyguide.pdf

8. de Souza AC, Alexandre NM, Guirardello EB. Psychometric properties in instruments evaluation of reliability and validity. Epidemiol Serv Saúde. 2017;26(3):649-59.

9. Garcia AB, Maziero VG, Rocha FL, Bernardes A, Gabriel CS. Influence of organizational culture on participatory management in health organizations. J Res Fundam Care Online. 2015;7(2):2615-27.

10. Bodur S, Filiz E. A survey on patient safety culture in primary healthcare services in Turkey. Int J Qual Health Care. 2009;21(5):348-55.

11. Tabrizchi N, Sedaghat M. The First Study of Patient Safety Culture in Iranian Primary Health Centers. Acta Med Iran. 2012;50(7): 505-10.

12. Paese F, Sasso TM. Patient safety culture in primary health care. Texto Contexto Enferm. 2013;22(2):302-10.

13. Rodríguez-Cogolloa R, Paredes-Alvaradoa IR, Galicia-Floresa $T$, Barrasa-Villarb JI, Castán-Ruizc S. [Patient safety culture in family and community medicine residents in Aragon]. Rev Calid Asist. 2014;29(3):143-9. Spanish.

14. Navarro AS, Guimaraes RL, Garanhani ML. [Teamwork and its meaning to professionals working in the family health strategy program]. Rev Min Enferm. 2013;17(1):69-75. Portuguese.

15. Santos RR, Lima EF, Freitas PS, Galavote LS, Rocha SE, Lima RC. The role of teamwork in Primary Health Care]. Rev Bras Pesq Saúde. 2016;18(1):130-39. Portuguese.

16. Ghobashi MM, El-ragehy HA, Ibrahim HM, Al-Doseri FA. Assessment of Patient Safety Culture in Primary Health Care Settings in Kuwait. Epidemiol Biostat Public Health. 2014;11(3):e9101-1-9.

17. Edwards MT. An Organizational Learning Framework for Patient Safety. Am J Med Qual. 2017;32(2)148-55.

18. Cunha EM, Giovanella L. [Longitudinality/continuity of care: identifying dimensions and variables to the evaluation of Primary Health Care in the context of the Brazilian public health system]. Ciênc Saúde Coletiva. 2011;16(1):1029-42. Portuguese.

19. Webair HH, Al-Assani SS, Al-Haddad RH, Al-Shaeeb WH, Bin Selm MA, Alyamani AS. Assessment of patient safety culture in primary care setting, Al-Mukala, Yemen. BMC Fam Pract. 2015;16(1):136.

20. Marchon SG, Mendes WV Junior. Patient safety in primary health care: a systematic review. Cad Saúde Pública. 2014;30:1815-35.

21. Onocko-Campos RT, Ferrer AL, Gama CA, Campos GW. Trapé TL, Dantas DV. [Assesment of quality of access in primary care in a large Brazilian city in the perspective of users]. Saúde Debate. 2014;38(Spe):252-64. Portuguese.

22. Lima EF, Sousa Al, Leite FM, Lima RC, Souza MH, Primo CC. Evaluation of the Family Healthcare Strategy from the Perspective of Health Professionals. Esc Anna Nery Rev Enferm. 2016;20(2):275-80. 
23. Siman AG, Cunha SG, Brito MJ. The practice of reporting adverse events in a teaching hospital. Rev Esc Enferm. USP. 2017;51:e03243.

24. Farah BF, Dutra HS, Sanhudo NF, Costa LM. [Perception of nurse supervisors on leadership in primary care]. Rev Cuid. 2017;8(2):163855. Portuguese.
25. Ritcher JP, McAlearney AS, Pennell ML. Evaluating the effect of safety culture on error reporting: a comparison of managerial and staff perspectives. Am J Med Qual. 2014;30(6):550-8.

26. Chakravarty BA. A survey of attitude of frontline clinicians and nurses towards adverse events. Medic J Armed Forces India. 2013;69(4):335-40.

\section{Acta Paul Enferm. 2018; 31(4):409-16.}

